Article

\title{
Applicability Evaluation of China's Retail Electricity Price Package Combining Data Envelopment Analysis and a Cloud Model
}

\author{
Yongxiu He ${ }^{1,2}$, Meiyan Wang ${ }^{1,2, *(\mathbb{D})}$ and Fengtao Guang ${ }^{1,2}$ \\ 1 School of Economics and Management, North China Electric Power University, Beijing 102206, China; \\ yongxiuhe@126.com (Y.H.); guang@ncepu.edu.cn (F.G.) \\ 2 Beijing Key Laboratory of New Energy and Low-Carbon Development (North China Electric Power \\ University), Beijing 102206, China \\ * Correspondence: 15538120475@163.com; Tel.: +86-010-6177-3113
}

Received: 30 October 2019; Accepted: 13 December 2019; Published: 18 December 2019

\begin{abstract}
With the reform of the power system, the retail electricity market in China has gradually been liberalized. The mechanism of freely selling electricity have been set up. To grab market share and increase profits, electricity retail companies have introduced a series of retail electricity price packages. To evaluate the applicability of these retail electricity price packages, an adaptive evaluation index system that takes into account the interests of both the power company and the users is first established. Furthermore, an integrated evaluation model that combines data envelopment analysis (DEA) and the cloud model is proposed. In this model, DEA is used to process quantitative indicators and the cloud model is employed to quantify qualitative problems. A case study of Tianjin is conducted to verify the effectiveness of the proposed evaluation system and model. The empirical study shows that qualitative indicators can also affect the applicability of the retail electricity price packages, and the applicability of the retail electricity price package was different in different seasons. Finally, several reliable suggestions on how to design retail electricity price packages are given based on the research. This study provides useful support for customers to choose the price package to increase the competitiveness of power selling companies and ultimately promote the reform of power selling.
\end{abstract}

Keywords: retail electricity price package; applicability evaluation; data envelopment analysis (DEA); cloud model; retail electricity market

\section{Introduction}

Since the deregulation of the retail electricity market in China, there has been a rapid increase in the number of electricity retail companies [1,2]. According to incomplete statistics, by the end of March 2018, there were more than 3342 electricity retail companies registered nationwide [3]. As new participants enter the market, electricity consumers are given a chance to choose from among a number of different retailers [4]. Due to the increased competition, consumers are encouraged to switch electricity retailers, which, in turn, poses risks to electricity retail companies, thus affecting the retail electricity market.

Consumers needs and behaviors have continued to change as the era progresses and technologies advance. Consequently, relationships between consumers and grids or utilities are being altered [5]. The components and relationships in retail competition are diverse and complicated, in comparison to a simple provider and customer relationship in the traditional electricity industry [6]. In particular, there is a diverse scale of retailers that can exist in the retail electricity market, which is different from 
the vertically integrated, monopoly-dominated market where only state-owned utilities are present. Facing an increasingly competitive power market, electricity retail companies can be expected to design diverse retail electricity price packages to adapt to the market environment, meet the differentiated needs of consumers, and improve the economic benefits of electricity retail companies. Combined with the objectives of retail electricity price package design, this paper evaluates the applicability of retail electricity price package from three dimensions: retail electricity market, electricity consumers and electricity retail companies.

Following the new electric power structural reform, the retail electricity market environment became the essential factor affecting the adaptability of retail price [7]. Scholars have quantitatively analyzed how competitiveness in both the wholesale and retail electricity market led to price decreases from 2014 to 2017 in Singapore, using daily data for electricity and oil prices. The research found that supply competition and the more recent retail liberalization has possibly led to a combinatorial decrease in electricity prices by up to $9.11 \%$ [8]. Similarly, power supply competition and retail liberalization may lead to a decline in electricity prices in Singapore's retail market [9]. However, the situation of electricity industry restructuring in the United States shows that restructured states have higher electricity rates than non-restructured states. This will affect the welfare and satisfaction of electricity customers [10]. The above research results show that the effects of retail market on the electricity prices are different. The following studies verify this conclusion. The scholars applied the asymmetric price transmission modelling technique to conduct a quantitative analysis of the Hungarian electricity trading market of the partially and the fully liberalized period. The research has found that different period lead to different influence for price transmission [11]. There have other factors of market that affect the retail price. Many scholars have analysed the influence of electric power market reform environment on electricity price based on the random effects model, independent power producers were found, privatization, structural adjustment and deregulation led to lower electricity prices [12]. In the Alberta's competitive retail electricity market context, using retail product price and characteristic data from July 2006 to March 2017, the analysis of product regulation on competitive retail electricity market development and retailer pricing decisions. The econometric analysis shows that the supervision effect is not obvious [13]. It can be seen that the most existing researches mainly concentrate on the impact of market competition on retail electricity price, but pay little attention to the operation efficiency, price mechanism and power supply and demand relationship of the retail electricity market.

The electricity retail companies first design retail electricity price packages, but the consumers reaction will affect the goals of package. Based on user preference and response efficiency to analysis the impact of flexible appliances on electricity prices $[14,15]$. The interaction between the retailer and consumers model is constructed by means of bi-level (BL) programming. The retailer sets the prices to be charged to consumers and these react by scheduling flexible appliances according to those prices and their comfort requirements [16]. Since load patterns can directly affect the supply cost of electricity, thus how to develop innovative retailing strategies with the help of appliance identification and behavior analysis of end-users is an important problem concerned by electricity retailers [17]. Scholars put forward novel approach to optimize the retail electricity price of household appliances is proposed, which makes consumers to reduce the electricity cost reasonably by improving the household consumption mode [18,19]. Therefore, the retailer faces a trade-off between selling prices and customers' consumption and power consumption mode.

Motivation and problem description in restructured retail electricity markets, electricity retail companies are profit-based entities which purchase electricity from the wholesale market with volatile prices and sell it to the consumers with a specified tariff [20]. Electricity price and demand level are the most important uncertainties for retailers [21]. The scholars studied electricity sales profits and electricity consumption costs to evaluate the economics of electricity prices [22-24]. The higher selling price increases clients switching probability to rivals that reduces the retailer s expected income. This paper presents a fuzzy Information Gap Decision Theory (IGDT) based framework for electricity 
retailers to specify the energy acquisition strategy. Clients reaction to retail-selling prices is incorporated into the framework via fuzzy numbers. The retailer discussed the trade-off between selling prices and clients consumption based on the framework [25]. The scholars use data from Texas to examine whether post-reform retail prices will reduce retailer costs. The research found clear evidence of outcomes in competitive market areas but not in non-competitive areas supplied by municipally-owned utilities or co-operatives [26]. The previous studies regarding the evaluation of electricity prices does not consider the customer lifetime value.

Based on the above discussion, this paper established an evaluation indicator system of the applicability of retail electricity price packages from three dimensions: retail electricity market, electricity consumers and electricity retail companies. The quantitative indicators include market operating efficiency, peak-valley ratio, user power utility, users' electricity use satisfaction, market share and customer lifetime value of the electricity sales company. The qualitative indicators include the price mechanism of the retail electricity market, the differentiated demands of electricity-use and the risk prevention mechanism in electricity sales company.

It is necessary to establish a scientific and effective assessment model to comprehensively evaluate the applicability of the retail electricity price packages on the basis of a sound evaluation index system for applicability of the electricity price packages. Most studies used analytic hierarchy process, fuzzy synthetic evaluation and principal component analysis to estimate the electricity price, but these models require one to determine the weight of each evaluation factor by an expert scoring method. This paper uses data envelopment analysis (DEA) to analyse the quantitative indexes of retail electricity price packages. For the evaluation of multiple sets of data, the data envelopment analysis (DEA) as a non-parametric data-driven method can be used to measure the relative performance between a group of decision-making units (DMUs). DEA is a quantitative analysis method to evaluate the relative effectiveness of multiple input indicators and multiple output indicators [27]. The linear programming method is used to evaluate the input and output data of each decision unit, and the efficiency score is finally obtained [28]. Tianjia adopted the panel data coving for regions between 2001 and 2007 to analyze the power efficiency using DEA, and its influencing factors were analyzed to explain the reason for the differences in electricity consumption efficiency across different regions [29]. Patricia et al. combined the life cycle assessment and DEA to comprehensively assess the sustainable development of the power structure of the $28 \mathrm{EU}$ member states from three dimensions of economic, environmental and social performance in 2015 [30]. The advantage of DEA is that it obtains the optimal weight using the actual data from multiple inputs and outputs of the decision unit, and does not need to perform dimensionless data processing. DEA is fit for the multi-agent and multi-index evaluation characteristics of the retail electricity price package, and increases the objectivity of the evaluation result [31].

Concerning research on the qualitative evaluation of applicability, the clouds model is one for transformation between qualitative and quantitative knowledge by $\mathrm{Li}$, a Chinese scholar [32]. It uses forward cloud transformation (FCT) and reverse cloud transformation (RCT) to realize cognitive transformation between concept connotation and extension [33]. Chao-Qun constructed an improved cloud model based on an analytic hierarchy process (AHP) to evaluate the relationship between sustainability and mineral resources. Its results showed that sustainability and resource richness are not positively correlated [34]. Wen used information to define relative entropy and modified relative entropy as the distance measure of the normal cloud model; it analyses the influence of uncertainty factors such as information and time on risk, and verifies the rationality of the analysis method [35]. Song combined the qualitative analysis of the cloud model and the quantitative analysis of extension theory were combined to establish an evaluation model of power market operation efficiency based on extension cloud theory [36]. The cloud model integrates the fuzziness and randomness of qualitative index, which can expertly analysis the subjective applicability factors involved in retail electricity price packages and implement the mapping between qualitative and quantitative indexes. 
Given this background, an applicability evaluating model for the retail electricity price package that combines data envelopment analysis (DEA) and the cloud model is proposed in this work. This paper aims to comprehensively evaluate the applicability of retail electricity price package, and demonstrate whether it will affect the evaluation results after introducing qualitative indexes to applicability evaluation. The empirical study shows that qualitative indicators can also affect the applicability of the retail electricity price packages. Therefore, combining the quantitative indicators with the qualitative ones provides a more accurate scientific evaluation of the applicability of the retail electricity price package. In addition, we found that the applicability of the retail electricity price package was different in different seasons. The applicability of sumner and winter is low, which may be related to the influence of seasonal temperature change on user load.

The contributions of this paper and the difference with the existing literature are as follows: Firstly, by taking into account the characteristics of China's retail electricity market reform in different stages, the long-term economic benefits of electricity retail companies and the differentiated demand for different electricity consumers. We establish an evaluation indicator system of the applicability of retail electricity price packages. Secondly, we construct an applicability evaluation model of retail electricity price packages based on DEA and the cloud model to help obtain more objective results. Finally, considering the seasonal fluctuation of user load and the seasonal differences in electricity prices, the year is divided into four periods: spring, summer, autumn and winter from the three dimensions of the retail electricity market, electricity retail company and consumers. We discussed the adaptability level of the retail electricity price package, and give some suggestions for its improvement. The results of the study are helpful for the electricity retail companies to improve the retail electricity price packages, guide the customers to choose the appropriate price package, and promote the reform of the retail electricity market. At the same time, the conclusions of this dissertation provide directions for the policy makers. To the best of our knowledge, no studies have evaluated the applicability of China's retail electricity price package, and this study thus contributes to the literature in this area.

The remainder of this paper is structured as follows: Section 2 proposes the applicability evaluation index system of retail electricity price packages, including quantitative and qualitative indicators, based on the interests of the retail electricity market, electricity retail companies and electricity consumers. Section 3 outlines the construction of the applicability evaluation model, which mainly includes the construction of both a quantitative evaluation model based on DEA and a qualitative evaluation model based on the cloud model. Section 4 provides an evaluation of the applicability of retail electricity price packages of Tianjin and put forward optimization suggestion for retail electricity price packages. We also verify the effectiveness of the model based on customer lifetime value. The final section gives the conclusions and future prospects of the study.

\section{Adaptability Evaluation Index of Electric Price Packages}

According to the load characteristics of electricity users, electricity sale companies will combine different types of electricity price and electricity tariff levels to formulate retail electricity price packages, and provide certain preferential measures to users based on the differentiated electricity demand for various target customers. The goal of the retail electricity price package design is to adapt to the new electricity market price policy and the power market competition environment, as well as to achieve the electricity sales company's strategic goals and economic efficiency goals. Finally, it should meet the power users' electricity demand and reduce electricity costs. According to these aspects, an adaptive evaluation index system for retail electricity price packages is built, as shown in Figure 1. 


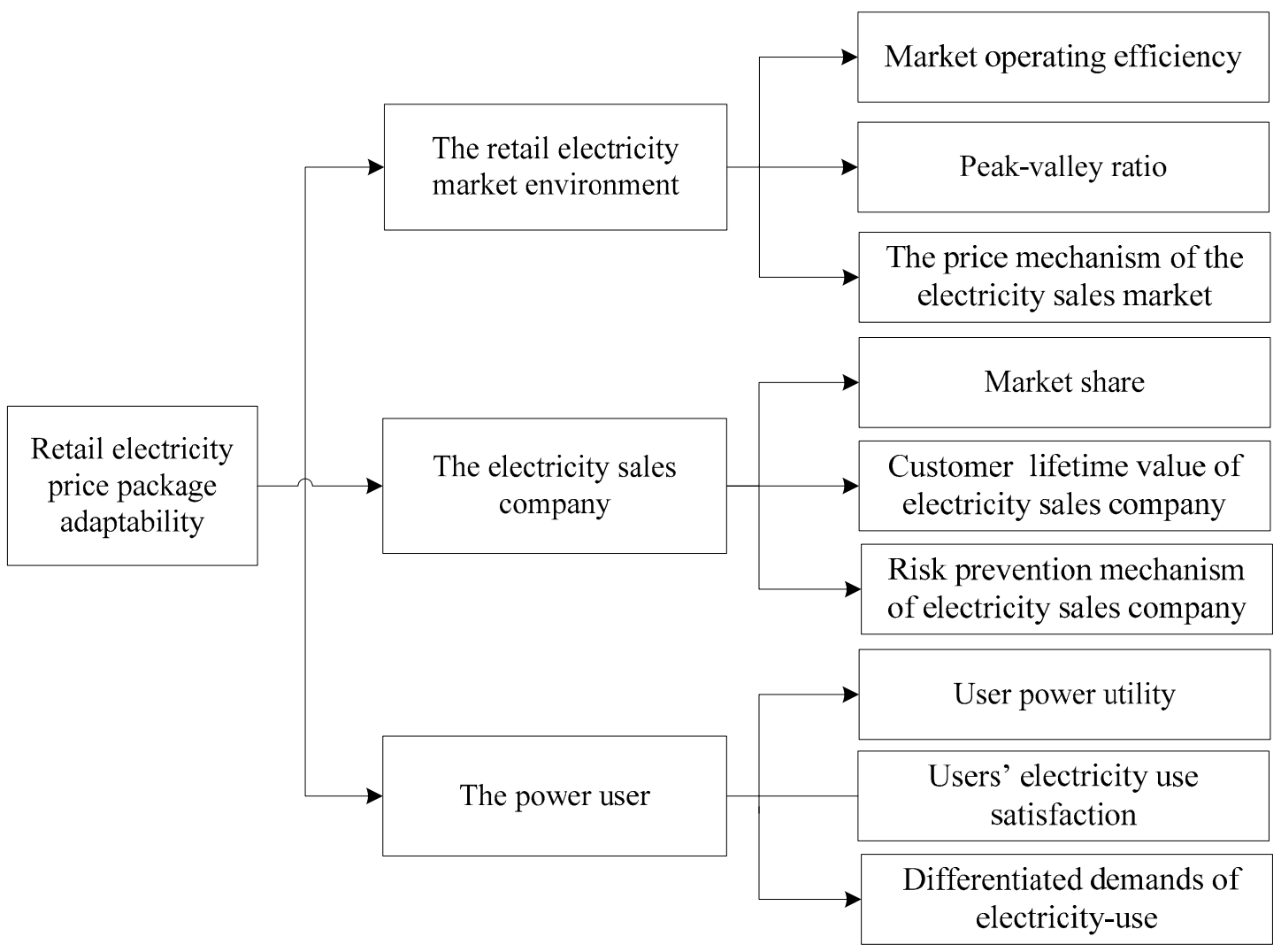

Figure 1. Adaptability evaluation index system of electric price packages.

\subsection{Quantitative Index of Applicability Evaluation of Retail Electricity Price Packages}

\subsubsection{Market Operating Efficiency}

The operational development of the electricity sales market is closely related to the rational design of retail electricity price packages, and they continuously promote and improve each other [37]. Retail electricity price packages should adapt to the market operation efficiency at different stages of the electricity market reform [38]. Market efficiency $(M E)$ is the ratio of marginal cost to transaction price:

$$
M E=\frac{M C}{P}
$$

where $M E$ represents market efficiency, $M C$ represents the marginal cost of the retail electricity price package, $P$ represents the transaction price of the retail electricity price package. A smaller $M E$ indicates a greater price deviation from the cost and a lower market efficiency; a $M E$ closer to 1 means that the price is closer to the cost and the market is more competitive.

\subsubsection{Peak-Valley Ratio}

The retail electricity price package should adapt to the peak and valley level of the electricity sales market. If the peak-to-valley electricity price ratio is too high, the user will overreact to the electricity price, and the peak-valley period will have a large drift, and peak-to-valley inversions will even occur. At the same time, the economic benefits of the electricity sales company will be impaired. If the peak-to-valley electricity price ratio is too low, the user's response will be insufficient, which will affect the sales of the electricity price package. The peak-valley ratio reflects the adaptation of the retail electricity price level. The expression is as follows:

$$
\rho_{f}=\frac{P_{L \cdot \max }-P_{L \cdot \min }}{P_{L \cdot \max }}
$$


where $\rho_{f}$ represents peak-valley ratio, $P_{L \text {.max }}$ represents the daily peak load and $P_{L \text {.min }}$ represents the daily minimum load.

\subsubsection{User Power Utility}

The user's electricity utility reflects whether the retail electricity price package can reduce the user's electricity cost. The difference between the consumption budget and the consumption amount of the retail electricity price package reflects the benefits of the retail electricity price package of the user's choice [39]. Compared with the existing electricity consumption mode, the greater the difference, the more the users are inclined to purchase the retail electricity price package. We define this difference as a utility value, expressed as:

$$
\begin{gathered}
U_{i j}=B_{c}-R_{i j},(i=1,2, \cdots, I ; J=1,2, \cdots J) \\
R_{i j}=\sum_{k=1}^{K}\left(q_{i j} \times P_{j k}\right)+P_{c j}(i=1,2, \cdots, I ; J=1,2, \cdots J)
\end{gathered}
$$

where $U_{i j}$ represents the utility for the $i$-th user when selecting the $j$-th retail electricity price package scheme. $B_{\mathcal{C}}$ represents electricity charges for traditional electricity consumption modes. $R_{i j}$ represents the electricity charge for the $i$-th user when selecting the $j$-th retail electricity price package scheme. $q_{i k}$ represents the estimated electricity consumption of the $i$-th user in the $k$-th time period. $P_{j k}$ represents the electricity price for the $j$-th retail electricity price package in the $k$-th time period. $P_{c j}$ represents the capacity price of the $j$-th retail electricity price package. I represents the total number of users. $J$ represents the total number of retail electricity price package schemes. Finally, $K$ represents the total period.

\subsubsection{Users' Electricity Use Satisfaction}

Before the retail electricity price package is executed, the electricity price is equal for each time period, and the user will not transfer the load because of the retail electricity price. Consequently, the user will choose the most comfortable mode, and usually set it as the reference value of the user's electricity satisfaction degree [40]. When the retail electricity price package is executed, the user changes their own power consumption mode due to changes in the electricity price. Subsequently, a new load curve is formed. Therefore, the user's satisfaction in the electricity-use is obtained according to the difference between the power consumption of the time period and the reference value after the implementation of the retail electricity price package. The user's satisfaction of electricity-use is:

$$
E C S=1-\frac{\sum_{k-1}^{24}\left|Q^{\prime}{ }_{k}-Q_{k}\right|}{\sum_{k-1}^{24} Q_{k}}
$$

where ECS represents the user's satisfaction with the electricity use, $Q_{k}$ represents the electricity consumption for the $k$-th period before the retail electricity price package is executed and $Q_{k}^{\prime}$ represents the electricity consumption for the $k$-th period after the retail electricity price package is executed.

\subsubsection{Market Share}

The market share reflects the competitiveness of the retail electricity price package, and it is an vital measure of whether the electricity retail company can launch the package. Assuming that the user is rational, the user's purchase of the product is determined by its utility. The simulation of the user's 
choice of the retail electricity price package is based on the probabilistic selection rule [41], which is expressed as:

$$
P_{i j}=\frac{e^{\mu U_{i j}}}{\sum_{j=1}^{J} e^{\mu U_{i j}}}(i=1,2, \cdots, I ; J=1,2, \cdots, J)
$$

where $P_{i j}$ represents the market share of the $j$-th retail electricity price package scheme, $U_{i j}$ represents the utility for the $i$-th user when selecting the $j$-th retail electricity price package scheme, $J$ represents the number of all products that may appear on the market (including competitive retail electricity price packages and existing retail electricity price packages of electricity retail companies) and $\mu$ is a proportion parameter: the larger the value, the closer the model to the deterministic rule; the smaller the value, the more it approximates uniform distribution.

\subsubsection{Customer Lifetime Value of the Electricity Sales Company}

Customer lifetime value indicates the total amount of revenue that the user's purchases on the retail electricity price package may bring to the enterprise in the future. If the customer lifetime value is higher than the existing electricity sales model income, it means that the retail electricity price package is economically reasonable, which can be expressed as:

$$
\begin{gathered}
B_{C L V}=\sum_{T=1}^{T} \sum_{i=1}^{I} \frac{Q_{i} r_{t}}{(1+d)^{t}}\left(\sum_{j=1}^{J}\left(R_{i j}-C_{j}^{v}\right) P_{i j}\right)-C^{M}-C^{F} \\
r_{t}=f^{K}(t)(t=1,2, \cdots, T)
\end{gathered}
$$

where $B_{C L V}$ represents the total customer lifetime value, $T$ represents the customer life cycle length, $I$ represents the number of market segments, $Q_{i}(i=1,2, \cdots, I)$ represents the number of potential users in the market segment, $r_{t}$ is the user retention rate for the $t$ th moment in the market, $f^{K}(t)$ is a function of the customer retention rate change over time, $d$ represents the discount rate, $J$ represents the number of plans for the introduction of retail electricity price packages, $R_{i j}$ represents the cost to the customer to purchase the retail electricity price package, $C_{j}^{v}$ represents the variable cost of retail electricity price packages in the $i$-th market, $P_{i j}$ represents the probability that the user of the $i$-th segment will choose the $j$-th tariff plan, $C^{M}$ represents the management fee associated with the package plan and $C^{F}$ represents a fixed cost.

\subsection{Qualitative Indicators for Applicability Evaluation of Retail Electricity Price Packages}

\subsubsection{Adaption to the Price Mechanism of the Electricity Sales Market}

In the price mechanism of the electricity sales market, the on-grid price and the user's electricity price will gradually establish the market pricing, and the retail electricity price package provided by the electricity sales company will become the key to its market competition. When the retail electricity price package meets the market supply and demand relationship and the electricity price trend, it will guarantee the price advantage in the electricity sales market.

\subsubsection{Adaption to the Risk Prevention Mechanism in Electricity Sales Company}

The electricity sales market does have uncertainties, such as users' electricity consumption and future market returns. Therefore, the electricity price package should have the ability to cope with uncertain factors to minimize market risks. 


\subsubsection{Adaption to the Differentiated Demands of Electricity-Use}

The development of social economy diversifies the demand for electricity use. Whether it can provide differentiated power products according to the different needs of customers is a vital indicator of the rationality of electricity price package designs.

\section{Comprehensive Evaluation Model of the Applicability of Retail Electricity Price Packages}

Considering the characteristics of the applicability evaluation index system for retail electricity price packages, we combined DEA and the cloud model to construct a comprehensive evaluation model to evaluate their applicability.

The DEA method does not need to determine the relational expressions between the input and the output. Moreover, because the optimal weight is determined based on the actual data of the decision units, the DEA could lead to the evaluation result with strong objectivity. The cloud model is proposed based on both the stochastic and fuzzy mathematics. It is able to better analyse the uncertainty of the qualitative index of retail electricity price packages. It can also transform the qualitative index into a quantitative one and obtain accurate evaluation results.

\subsection{Data Envelopment Analysis of the Quantitative Index}

The DEA is used to evaluate the quantitative index of the retail electricity price package and here the DEA-C2R model [42] is selected to deal with the multiple inputs and outputs involved in the retail electricity price package.

Taking the retail electricity price package as the evaluation $D M U_{s}$, there are multiple $D M U_{j}$ according to the established evaluation index system; each $D M U_{j}$ has $p$ quantitative indicators, and the index values of inputs in $t$ periods are:

$$
D M U_{j}=\left[\begin{array}{cccc}
x_{P_{j} 11} & x_{P_{j} 21} & \cdots & x_{P_{j} t 1} \\
x_{P_{j} 12} & x_{P_{j} 22} & \cdots & x_{P_{j} t 2} \\
\vdots & \vdots & \ddots & \vdots \\
x_{P_{j} 1 p} & x_{P_{j} 2 p} & \cdots & x_{P_{j} t p}
\end{array}\right]
$$

where $x_{P_{j} i j}$ represents the value of the $j$-th quantitative indicator corresponding to the retail electricity price package $P_{j}$ in the $i$-th period.

The value of the quantitative index was analysed and solved by the DEA-C2R model, and the relative efficiency evaluation index of the retail electricity price package $P_{j}$ in $t$ periods was obtained as follows:

$$
\theta_{P_{j}}=\left[\theta_{P_{j} 1}, \theta_{P_{j}}, \cdots, \theta_{P_{j} t}\right]
$$

where $\theta_{P_{j}}$ is the efficiency evaluation result of the $j$-th retail electricity price package.

Following the same process, the efficiency evaluation result matrix of the $k$ retail electricity price package $p_{1}, p_{2}, \cdots, p_{k}$ in t periods is:

$$
\theta_{P_{j}}=\left[\begin{array}{cccc}
\theta_{P_{1} 1} & \theta_{P_{1} 1} & \cdots & \theta_{P_{1} t} \\
\theta_{P_{2} 1} & \theta_{P_{2} 2} & \cdots & \theta_{P_{2} t} \\
\vdots & \vdots & \ddots & \vdots \\
\theta_{P_{k} 1} & \theta_{P_{k} 2} & \cdots & \theta_{P_{k} t}
\end{array}\right]
$$

In summary, the DEA evaluation process for the retail electricity price package is shown in Figure 2. 


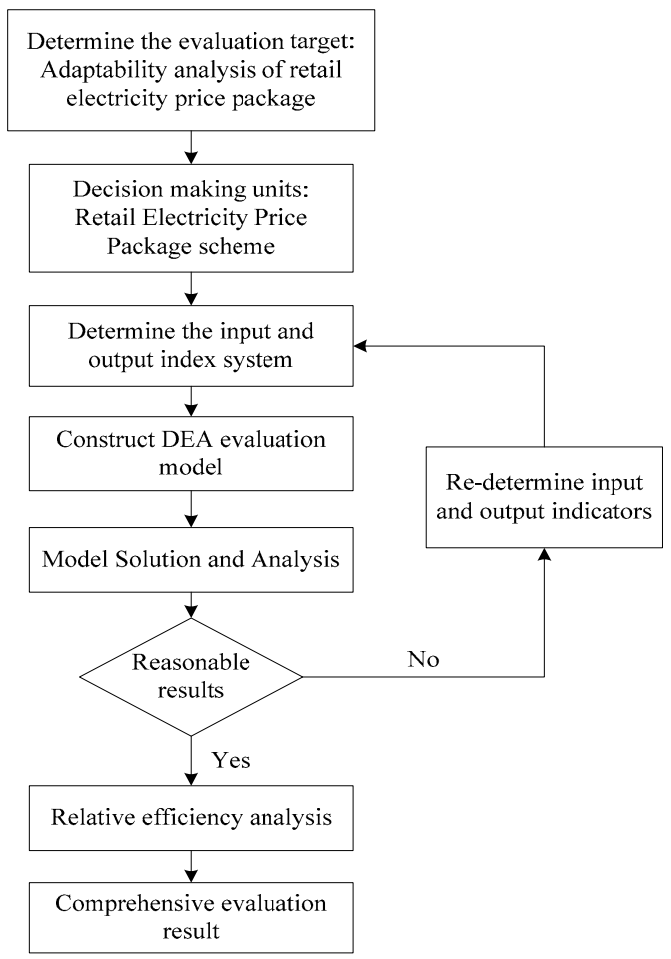

Figure 2. The DEA evaluation steps of the Retail Electrical Price Package.

\subsection{Analysis of the Cloud Model of Qualitative Index}

This paper uses cloud model to analyze the qualitative index of the retail electricity price package. The fuzziness and randomness of the qualitative index are fully integrated, and the normal cloud model is used to process them [43].

Assuming that the retail electricity price package $P_{j}$ has $q$ qualitative evaluation indexes. According to the measurement standard, the expert determines that the membership degree $\alpha$ of the index meets $0 \leq \alpha \leq 1$. The membership degree of the relative standard value of $q$ qualitative indexes of retail electricity price package $P_{j}$ in $i$-th period is $\left[\alpha_{P_{j} i 1}, \alpha_{P_{j} i 2}, \cdots, \alpha_{P_{j} i q}\right](1<i<t)$. The cloud digital eigenvalue of the $d$ - th qualitative index of the retail electricity price package $P_{j}$ calculated by the reverse cloud model is $\left[E_{I I P_{j} d}, D_{\prime I I P_{j} d}, H_{\prime I I P_{j} d}\right]$, where the subscript $I I$ represents the result of qualitative index analysis. Similarly, we can get the cloud digital eigenvalue matrix of all qualitative indicators of retail electricity price package $P_{j}$ in $t$ periods.

$$
R_{I I}=\left[\begin{array}{ccc}
E_{I I P_{j} 1} & D_{I I P_{j} 1} & H_{I I P_{j} 1} \\
E_{I I P_{j} 2} & D_{I I P_{j} 2} & H_{I I P_{j} 2} \\
\vdots & \vdots & \vdots \\
E_{I I P_{j} q} & D^{\prime} I I P_{j} q & H_{I I P_{j} q}
\end{array}\right]
$$

In this paper, the reverse cloud model is used to obtain the E, D and $\mathrm{H}$ of the cloud. The steps are as follows:

Step 1: Input sample point $x_{1}(i=1,2, \cdots, n)$. According to the input sample $x_{1}$, calculate the overall mean $\bar{X}=\frac{1}{n} \sum_{i=1}^{n} x_{i}$.

Step 2: Calculate the 1st order absolute centre distance of the sample $\frac{1}{n} \sum_{i=1}^{n}\left|x_{i}-\bar{X}\right|$; calculate the variance of the sample $S^{2}=\frac{1}{n-1}\left(x_{i}-\bar{X}\right)^{2}$.

Step 3: Calculate $E=\bar{X}$. 
Step 4: Calculate $D=\sqrt{\frac{1}{2}} \cdot \frac{1}{n} \sum_{i=1}^{n}\left|x_{i}-E\right|$.

Step 5: Calculate $H=\sqrt{\left|S^{2}-D^{2}\right|}$.

\subsection{Comprehensive Evaluation and Analysis of the Adaptability of Retail Electricity Price Packages}

\subsubsection{Fuzz the DEA Evaluation Results}

Firstly, the quantitative evaluation results of DEA are fuzzified, and then combined with the quantitative and qualitative evaluation results for comprehensive analysis. To integrate the evaluation results of the quantitative and qualitative indexes, it was necessary to blur the results of the quantitative evaluation of the DEA, before combining the quantitative and qualitative results to make a comprehensive analysis.

The reverse cloud model blurs the results of the quantitative index of DEA, first determining the weight of the relative efficiency on the total efficiency. According to expert scoring, assuming the number of experts is $l$, an expert gives the weight score as $h$, and adopts the centesimal grade of $0<$ $h<100$. The relative efficiency weight of the quantitative index of retail electricity price package $P_{j}$ is $\left[h_{P_{j} l}, h_{P_{j} l}, \cdots, h_{P_{j} l}\right]$. The reverse cloud model is used to obtain the cloud digital feature, which is $\left[E_{I P_{j}}, D_{I P_{j}}, H_{I P_{j}}\right]$, where the subscript I represents the quantitative index analysis results. The weighting score of the retail electricity price package $P_{j}$ quantitative indicator is:

$$
A_{I}=\left[E_{I P_{j}}, D_{I P_{j}}, H_{I P_{j}}\right]
$$

From Equation (10), the efficiency evaluation index of the retail electricity price package $P_{j}$ in the th period is $\theta_{P_{j}}$, and by using the reverse cloud model, the cloud digital feature can be obtained, which is $\left[E_{I P_{j}}, D^{\prime} I P_{j}, H_{I P_{j}}\right]$. The numerical characteristics of the quantitative index of the retail electricity price package $P_{j}$ are:

$$
R_{I}=\left[E_{I P_{j}}, D_{\prime I P_{j}}, H_{\prime I P_{j}}\right]
$$

Therefore, the analysis results of the quantitative indicators are as follows:

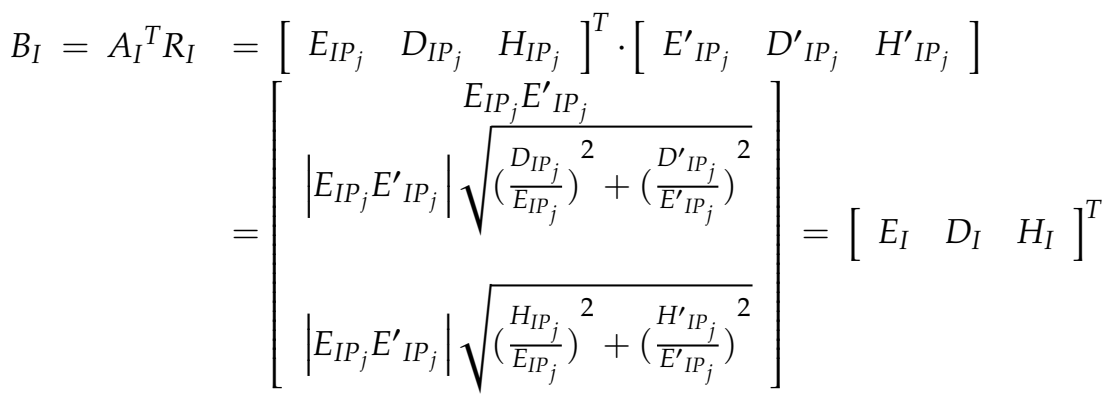

\subsubsection{Processing Cloud Model Results}

The weights of qualitative indicators are determined by experts. The weight (assumed to be d,1 $<\mathrm{d}<100$ ) of a qualitative indicator of the retail electricity price package $P_{j}$ relative to the overall indicator is assigned to $c$ by $l$ experts. The weight of this qualitative indicator of the retail electricity price package $P_{j}$ is $\left(c_{d 1}, c_{d 2}, \cdots, c_{d l}\right)$. The cloud digital feature $\left[E_{I I P_{j} d}, D_{I I P_{j} d}, H_{I I P_{j} d}\right]$ of the qualitative indicator weight can be obtained by using the reverse cloud model. 
Similarly, we can obtain the cloud digital characteristics of the $q$ qualitative index weights of the retail electricity price package $P_{j}$ :

$$
A_{I I}=\left[\begin{array}{ccc}
E_{I I P_{j} 1} & D_{I I P_{j} 1} & H_{I I P_{j} 1} \\
E_{I I P_{j} 2} & D_{I I P_{j} 2} & H_{I I P_{j} 2} \\
\vdots & \vdots & \vdots \\
E_{I I P_{j} q} & D_{I I P_{j} q} & H_{I I P_{j} q}
\end{array}\right]
$$

Therefore, the analysis results of the qualitative indicators are as follows:

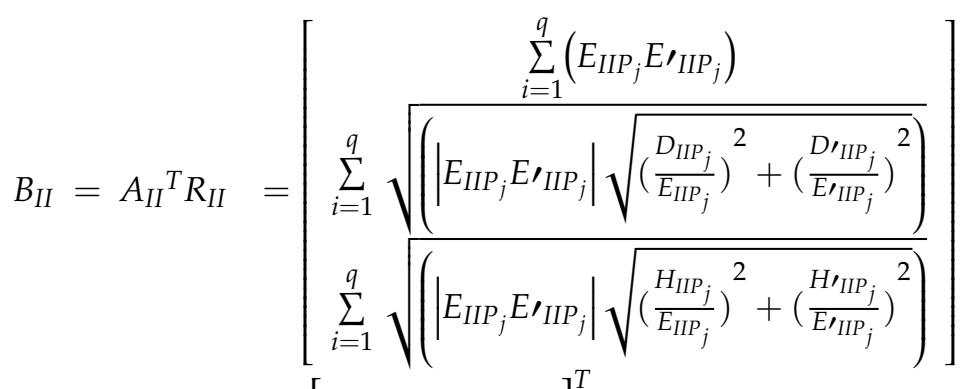

$$
\begin{aligned}
& =\left[\begin{array}{lll}
E_{I I} & D_{I I} & H_{I I}
\end{array}\right]^{T}
\end{aligned}
$$

\subsubsection{Comprehensive Applicability Evaluation}

The influence weight of the quantitative and qualitative indexes of the retail electricity price package $P_{j}$ on the applicability evaluation system is set to $v_{1}$ and $v_{2}$, respectively. Thus, the applicability comprehensive evaluation matrix is:

$$
B=\left[v_{1} v_{2}\right] \times\left[\begin{array}{c}
B_{I}^{T} \\
B_{I I}^{T}
\end{array}\right]=\left[\begin{array}{lll}
E & D & H
\end{array}\right]
$$

This is the applicability evaluation result of the retail electricity price package $P_{j}$. Following the same process, the applicability evaluation results of other retail electricity price packages can be obtained. According to the aforementioned analysis results, the applicability evaluation of the retail electricity price package can be ranked and the reasons for their low applicability can be analyzed.

\section{Case Study}

This paper used Tianjin power market-related data to verify the validity of the model. The model aims to analyze the adaptability of retail electricity price packages in the retail electricity market from the perspective of the power market reform, determining whether the packages can meet users' electricity demands and improve the economic performance of power selling enterprises.

\subsection{Basic Data}

Taking the Tianjin power market as an example, we chose four kinds of industrial retail electricity price packages as the object of our adaptive evaluation $(k=4)$. According to the seasonal characteristics of user load and the differences between various retail electricity price package levels, we analysed the applicability evaluation results of the retail electricity price packages over one year (four periods: $t=4)$. The data we used mainly included: the formula calculating result, the statistics report data of the Tianjin Electric Power Company, the relevant research reports and reasonable estimates based on the electricity market (The initial data of the dissertation mainly comes from the research project and can be disclosed. Some data are subject to confidentiality agreements and cannot be disclosed. Some of the data is from the official website at http://www.stats.gov.cn/.). The quantitative indicator results obtained after the implementation of the DEA are shown in Table 1. 
Table 1. DEA evaluation input and output data.

\begin{tabular}{|c|c|c|c|c|c|c|c|c|c|}
\hline \multicolumn{2}{|c|}{$\begin{array}{l}\text { Retail Electricity Price } \\
\text { Package Scheme }\end{array}$} & \multirow{2}{*}{$\begin{array}{c}\begin{array}{c}\text { Market } \\
\text { Efficiency (\%) }\end{array} \\
0.031\end{array}$} & \multirow{2}{*}{$\begin{array}{c}\begin{array}{c}\text { Peak-Valley } \\
\text { Ratio (\%) }\end{array} \\
0.435\end{array}$} & \multirow{2}{*}{$\begin{array}{c}\begin{array}{c}\text { Market } \\
\text { Share }\end{array} \\
0.218\end{array}$} & \multirow{2}{*}{$\begin{array}{c}\begin{array}{c}\text { Customer Lifetime } \\
\text { Value (yuan) }\end{array} \\
90,015.49\end{array}$} & \multirow{2}{*}{$\begin{array}{c}\begin{array}{c}\text { Utility of } \\
\text { Electricity (yuan) }\end{array} \\
2.729\end{array}$} & \multirow{2}{*}{$\begin{array}{l}\text { Satisfaction with the } \\
\text { Way Users Use } \\
\text { Electricity (\%) }\end{array}$} & \multirow{2}{*}{$\begin{array}{c}\begin{array}{c}\text { Electricity } \\
\text { Price }\end{array} \\
0.645\end{array}$} & \multirow{2}{*}{$\begin{array}{r}\begin{array}{c}\text { Cost } \\
\text { (yuan) }\end{array} \\
0.02\end{array}$} \\
\hline \multirow{4}{*}{ Scheme 1} & Summer & & & & & & & & \\
\hline & Spring & 0.035 & 0.604 & 0.219 & $66,720.68$ & 4.575 & 0.687 & 0.578 & 0.02 \\
\hline & Autumn & 0.035 & 0.705 & 0.229 & $126,999.6$ & 0.338 & 0.605 & 0.578 & 0.02 \\
\hline & Winter & 0.031 & 0.446 & 0.224 & $104,645.3$ & 1.837 & 0.842 & 0.643 & 0.02 \\
\hline \multirow{4}{*}{ Scheme 2} & Summer & 0.032 & 0.477 & 0.249 & $97,342.55$ & 3.066 & 0.803 & 0.616 & 0.02 \\
\hline & Spring & 0.036 & 0.568 & 0.248 & $70,174.04$ & 4.877 & 0.659 & 0.548 & 0.02 \\
\hline & Autumn & 0.036 & 0.654 & 0.280 & $146,434.5$ & 0.847 & 0.659 & 0.548 & 0.02 \\
\hline & Winter & 0.033 & 0.400 & 0.262 & $115,294.5$ & 2.219 & 0.896 & 0.613 & 0.02 \\
\hline \multirow{4}{*}{ Scheme 3} & Summer & 0.048 & 0.711 & 0.151 & $570,48.18$ & 1.820 & 0.557 & 0.731 & 0.035 \\
\hline & Spring & 0.055 & 0.852 & 0.181 & $43,866.93$ & 4.096 & 0.372 & 0.633 & 0.035 \\
\hline & Autumn & 0.055 & 1.181 & 0.166 & $85,140.87$ & 0 & 0 & 0.633 & 0.035 \\
\hline & Winter & 0.048 & 1.077 & 0.141 & $62,857.77$ & 0.684 & 0 & 0.728 & 0.035 \\
\hline \multirow{4}{*}{ Scheme 4} & Summer & 0.050 & 0.667 & 0.171 & $60,956.42$ & 2.131 & 0.605 & 0.703 & 0.035 \\
\hline & Spring & 0.058 & 0.824 & 0.202 & $45,108.91$ & 4.374 & 0.412 & 0.605 & 0.035 \\
\hline & Autumn & 0.058 & 1.163 & 0.201 & $96,657.82$ & 0.013 & 0 & 0.605 & 0.035 \\
\hline & Winter & 0.050 & 1.064 & 0.163 & 68,530 & 1.038 & 0 & 0.700 & 0.035 \\
\hline
\end{tabular}


The values of the other input parameters are illustrated in Table 2.

Table 2. Other input parameters.

\begin{tabular}{ccc}
\hline Variable Name & Unit & Data \\
\hline Retail electricity price package operating fixed costs & million yuan & 10 \\
Retail electricity price package variable cost & yuan & $7 / 8 / 14$ \\
Fund discount rate & $\%$ & 0.01 \\
Calibration parameters of MNL & $\%$ & 0.4 \\
\hline
\end{tabular}

We combined the index system of the retail electricity price package to construct an adaptive evaluation model, and optimal retail electricity price packages were achieved based on the evaluation results.

\subsection{Quantitative Index Analysis}

Based on the DEA model, we first analyze the adaptability of retail electricity price packages from an overall perspective, before analyzing the adaptability of electricity price packages from three dimensions: users, electricity sales companies and electricity sales markets. Considering the seasonal difference in electricity price levels in various packages, this paper takes a quarter as a period, and divides a year into four periods: spring, summer, autumn and winter. Analyze the applicability of retail electricity price package within one year. According to the retail electricity price package adaptability evaluation index system established in this paper, the cost and electricity price levels are the input indicators, and the effect of the retail electricity price package adaptability is the output indicator. Using calculations, the relative efficiency of scheme 1 in each period is obtained, as shown in Table 3 .

Table 3. Relative efficiency of retail price package adaptability.

\begin{tabular}{ccccc}
\hline Scheme P1 Adaptive Relative Efficiency & Spring & Summer & Autumn & Winter \\
\hline Overall adaptability & 1 & 1 & 1 & 1 \\
User adaptability & 1 & 1 & 0.79 & 0.988 \\
Adaptability of power selling company & 0.956 & 0.952 & 1 & 0.978 \\
Electricity market adaptability & 1 & 0.886 & 1 & 0.886 \\
\hline
\end{tabular}

Table 3 shows the relative efficiency of scheme 1 of retail electricity price package for four periods of a year. The applicability of retail price package is analyzed on the whole. The relative efficiency is always 1 in each season, which indicates that the retail electricity price package has better adaptability.

From users' point of view, although the electricity price is lower in the autumn than in the spring and summer, the utility of electricity is much lower than in the spring and summer when the cost is the same, so the relative efficiency is not 1 . Winter satisfaction levels with the way users use electricity is relatively good, but higher electricity prices affect the relative efficiency of this period.

From the perspective of the power sales company in analyzing the adaptability, when the price of the spring, summer and winter periods is higher than the autumn period, the market share and customer lifetime value are relatively low, so the relative efficiency is not 1.

From the perspective of the electricity market analysis of adaptability, when the spring and winter electricity prices are high, the market operation efficiency and peak and valley difference rate is relatively low, so the relative efficiency is not 1 .

On the whole, the retail price package adapts to the utility of electricity and power consumption mode of users, and will attract users to purchase the retail price package. The retail price package transaction is formed in a market-oriented way, which will significantly increase the number of market participants and expand the scale of market transactions. Meanwhile, it can create conditions for the increase of the market share of power selling companies and the achievement of economic goals. 
At the same time, the retail price package is suitable for the market operation efficiency and peak valley difference rate of the electricity market, which would ensure that the price mechanism of the retail price package can effectively reflect the change of power supply and demand, and effectively connect with the market-oriented trading mechanism. It will lay a solid foundation for orderly liberalizing the power price of competitive links, accelerating the establishment of the decisive role of the market in the allocation of power resources and better playing the role of the government.

Similarly, the relative efficiency of other electricity price packages is shown in Table 4.

Table 4. Relative efficiency of other retail price packages.

\begin{tabular}{ccccc}
\hline $\begin{array}{c}\text { Retail Electricity } \\
\text { Price Package } \\
\text { Plan }\end{array}$ & $\begin{array}{c}\text { Overall } \\
\text { Adaptability } \\
\text { Relative Efficiency } \boldsymbol{\theta}\end{array}$ & $\begin{array}{c}\text { Relative Efficiency } \\
\text { of User } \\
\text { Adaptability }\end{array}$ & $\begin{array}{c}\text { The Adaptive } \\
\text { Relative Efficiency of } \\
\text { the Sales Company }\end{array}$ & $\begin{array}{c}\text { The Relative Efficiency } \\
\text { of the Adaptability of } \\
\text { the Electricity Market }\end{array}$ \\
\hline 1 & {$[1,1,1,1]$} & {$[1,1,0.79,0.988]$} & {$[0.956,0.952,1,0.978]$} & {$[1,0.886,1,0.886]$} \\
2 & {$[1,0.986,1,1]$} & {$[1,0.96,0.823,1]$} & {$[0.886,0.889,1,0.936]$} & {$[1,0.889,1,0.917]$} \\
3 & {$[1,1,1,0.958]$} & {$[1,1,0,0.167]$} & {$[1,0.872,1,0.832]$} & {$[1,0.873,1,0.912]$} \\
4 & {$[1,1,1,0.983]$} & {$[1,1,0.003,0.237]$} & {$[1,0.849,1,0.81]$} & {$[1,0.862,1,0.915]$} \\
\hline
\end{tabular}

As can be seen in Table 4:

(1) Scheme 1 is relatively more efficient than the other three schemes. Put simply, the adaptability of scheme 1 is best. The main reason is that under the condition of low cost and electricity price level, the utility of users and satisfaction of electricity consumption mode are relatively high. The results show that the retail price package has a strong applicability in the user dimension and can meet the power demand of users in the power market. At the same time, the introduction of tariff package in the electricity market gives users the right to choose freely and increases the willingness of users to purchase tariff package.

(2) Scheme 2 has the highest electricity price in the summer compared to the other three periods, while its market efficiency, market share and customer lifetime value are relatively low. Therefore, its relative efficiency is not 1 . Overall, the relative efficiency of Scheme 2 is higher than that of schemes 3 and 4 . The main reason is that Scheme 2 has the largest market share and customer lifetime value when the cost and price level are the lowest. The results show that the retail price package has good applicability in the dimensions of power selling companies, has strong market competitiveness, and can achieve the economic goals of power selling companies.

(3) In schemes 3 and 4 , the electricity price is relatively high in winter, while the market efficiency and market share are the lowest, so the relative efficiency is not 1 . At the same time, the relative efficiency of users' adaptability is lower in autumn and winter, mainly because users' electricity utility and satisfaction in electricity use are low. On the whole, the market operation efficiency and peak valley difference rate of schemes 3 and 4 are relatively good, which shows that the retail price package has strong applicability in the dimension of electricity sales market and can promote the rapid development of electricity sales market. Considering the long-term development of the electricity price package, it is necessary to adjust the electricity price package to improve its adaptability.

The cloud digital characteristics of the relative efficiency of scheme 1 are obtained using the reverse cloud model as follows: $\left[E_{I P_{j}}, D_{I P_{j}}, H_{\prime I P_{j}}\right]=[0.9928,0.0046,0.0035]$.

The evaluation result of the relative efficiency of the retail electricity price package scheme 1 is $R_{I 1}=[0.9928,0.0046,0.0035]$.

Similarly, the relative efficiency cloud digital eigenvalues and the evaluation results of other retail electricity price package schemes can be obtained, as shown in Table 5 . 
Table 5. Cloud digital eigenvalue and evaluation results of relative efficiency.

\begin{tabular}{ccccc}
\hline $\begin{array}{c}\text { Retail Electricity Price } \\
\text { Package Scheme }\end{array}$ & $\begin{array}{c}\text { Relative } \\
\text { Efficiency } \boldsymbol{\theta}\end{array}$ & $\begin{array}{c}\text { Cloud Digital } \\
\text { Eigenvalues }(\boldsymbol{E}, \boldsymbol{D}, \boldsymbol{H})\end{array}$ & $\begin{array}{c}\text { Evaluation Results of } \\
\text { Relative Efficiency } \boldsymbol{R}\end{array}$ & Sort \\
\hline Scheme 1 & {$[1,1,1,1]$} & {$[0.9928,0.0046,0.0035]$} & {$[0.9928,0.0046,0.0035]$} & 1 \\
Scheme 2 & {$[1,0.986,1,1]$} & {$[0.9829,0.0103,0.0046]$} & {$[0.9829,0.0103,0.0046]$} & 2 \\
Scheme 3 & {$[1,1,1,0.958]$} & {$[0.961,0.0233,0.0174]$} & {$[0.961,0.0233,0.0174]$} & 4 \\
Scheme 4 & {$[1,1,1,0.983]$} & {$[0.9683,0.0233,0.0157]$} & {$[0.9683,0.0233,0.0157]$} & 3 \\
\hline
\end{tabular}

Table 5 contains the relative efficiency evaluation results $R$ of the retail electricity price packages. The expected values of schemes 1, 2, 3 and 4 are $0.9928,0.9829,0.961$ and 0.9683 respectively. Scheme 1 has the highest expectations, that is, Scheme 1 is the best, followed by schemes 2, 4 and 3 .

According to the digital eigenvalues of the cloud model of the four retail electricity price packages in Table 3, the corresponding normal cloud images 3a-3d are drawn, as shown in Figure 3, where the abscissa indicates the actual value of the relative efficiency. The horizontal coordinate corresponding to the highest point of the graph represents expectation.
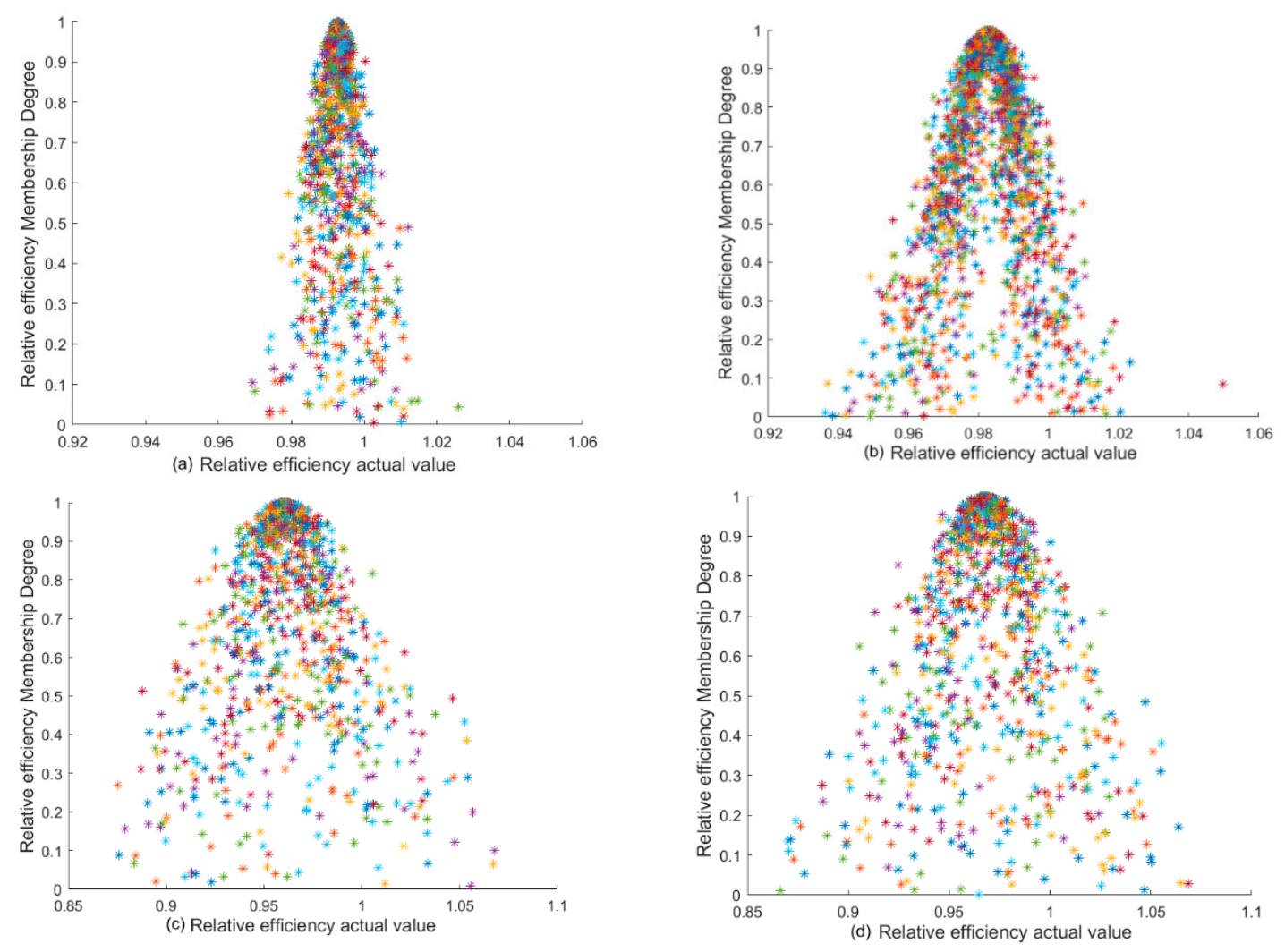

Figure 3. Normal cloud of relative efficiency of retail electricity price package scheme.

Figure 3 shows the cloud model of the four retail electricity price packages. The numerical eigenvalues of each cloud model are different, in which the expectation of Figure $3 \mathrm{a}$ is the largest, the entropy and super entropy of Figure $3 a$ is smaller than Figure $3 b$, and the overall graph is compact. The entropy and super entropy of Figure $3 \mathrm{c}, \mathrm{d}$ are relatively large, and the cloud droplets are dispersed throughout the graph. However, the bottom cloud droplets of Figure $3 \mathrm{~d}$ are more compact than Figure 3c. As a whole, Figure 3a, corresponding to retail electricity price package Scheme 1, is the best, followed by Schemes 2, Scheme 4 and Scheme 3.

We selected 35 power industry experts and 15 experts in other energy fields to determine the weight of the period applicability of the retail electricity price package on its overall applicability. According to Section 3.3.1, we can achieve an evaluation index weight according to the scoring results 
of expert $h$, and the digital eigenvalue of the cloud model of the statistical sample is calculated using the reverse cloud model: $A_{I}=[90.5,2.679,2.126]$.

Therefore, the evaluation result of the quantitative index of the retail electricity price package Scheme 1 is obtained: $B_{I}=A_{I}^{T} \cdot R_{I}=[89.848,2.692,0.001]$.

\subsection{Qualitative Index Analysis}

Considering that the retail electricity price package adaptability index includes several qualitative indicators, the DEA method cannot be used, thus the cloud model is introduced. According to the three objects in the retail electricity price package, this paper proposes three qualitative indicators: electricity market price mechanism, sales company risk prevention mechanism and differentiated demand for electricity, that is $q=3$.

According to the standards set out by experts, the membership degree of the three qualitative indicators relative to their standard values were obtained, as demonstrated in Table 6 .

Table 6. Membership degree of qualitative indicators.

\begin{tabular}{cccc}
\hline Scheme 1 & $\begin{array}{c}\text { Electricity Market } \\
\text { Price Mechanism }\end{array}$ & $\begin{array}{c}\text { Sales Company Risk } \\
\text { Prevention Mechanism }\end{array}$ & $\begin{array}{c}\text { Differentiated Demand } \\
\text { for Electricity }\end{array}$ \\
\hline Summer & 0.82 & 0.73 & 0.83 \\
Spring & 0.88 & 0.83 & 0.89 \\
Autumn & 0.87 & 0.88 & 0.69 \\
Winter & 0.81 & 0.71 & 0.77 \\
\hline
\end{tabular}

Using the reverse cloud model, we obtained the cloud model digital eigenvalues of the electricity market price mechanism, the sales company risk prevention mechanism and the differentiated demand for electricity in the four seasons:

$$
R_{I I}=\left[\begin{array}{lll}
E_{I I P_{j} 1} & D_{I I P_{j} 1} & H_{I I P_{j} 1} \\
E_{I I P_{j} 2} & D_{I I P_{j} 2} & H \prime_{I I P_{j} 2} \\
E_{I I P_{j} 3} 3 & D_{I I P_{j} 3} & H \prime_{I I P_{j} 3}
\end{array}\right]=\left[\begin{array}{ccc}
0.845 & 0.0209 & 0.00045 \\
0.7825 & 0.0467 & 0.0161 \\
0.79 & 0.0392 & 0.0285
\end{array}\right]
$$

We subsequently selected 50 experts to determine the weight of the three qualitative indexes of the electricity market price mechanism, the sales company risk prevention mechanism and the differentiated demand for electricity. According to the Section 3.3.1, we can achieve an evaluation index weight according to the scoring results of expert c, and the digital eigenvalue of the cloud model of the statistical sample is calculated using the reverse cloud model:

$$
A_{I I}=\left[\begin{array}{lll}
E_{I I P_{j} 1} & D_{I I P_{j} 1} & H_{I I P_{j} 1} \\
E_{I I P_{j} 2} & D_{I I P_{j} 2} & H_{I I P_{j} 2} \\
E_{I I P_{j} 3} & D_{I I P_{j} 3} & H_{I I P_{j} 3}
\end{array}\right]=\left[\begin{array}{ccc}
72.32 & 13.57 & 4.89 \\
76.51 & 10.32 & 2.54 \\
80.07 & 8.34 & 2.93
\end{array}\right]
$$

Therefore, the evaluation result of the qualitative index of retail electricity price package Scheme 1 is obtained:

$$
\begin{aligned}
B_{I I}=A_{I I}{ }^{T} R_{I I} & =\left[\begin{array}{ccc}
72.32 & 13.57 & 4.89 \\
76.51 & 10.32 & 2.54 \\
80.07 & 8.34 & 2.93
\end{array}\right]^{T} \times\left[\begin{array}{ccc}
0.845 & 0.0209 & 0.00045 \\
0.7825 & 0.0467 & 0.0161 \\
0.79 & 0.0392 & 0.0285
\end{array}\right] \\
& =\left[\begin{array}{lll}
180.283 & 24.0316 & 7.4029
\end{array}\right]^{T}
\end{aligned}
$$




\subsection{Applicability Comprehensive Evaluation}

The influence weight of the quantitative index and qualitative index of the retail electricity price package Scheme 1 on the overall applicability evaluation system is: $V=\left[\begin{array}{ll}v_{1} & v_{2}\end{array}\right]=\left[\begin{array}{ll}0.7 & 0.3\end{array}\right]$.

Similarly, the comprehensive evaluation result of the retail electricity price package Scheme 1 is $B=\left[\begin{array}{ll}v_{1} & v_{2}\end{array}\right] \times\left[\begin{array}{c}B_{I}^{T} \\ B_{I I}^{T}\end{array}\right]=\left[\begin{array}{ll}0.7 & 0.3\end{array}\right] \times\left[\begin{array}{ccc}89.848 & 2.692 & 0.001 \\ 180.283 & 24.0316 & 7.4029\end{array}\right]=[98.311,20.735,6.803]$.

Similarly, the comprehensive evaluation results of the applicability of other retail electricity price packages can be obtained, and the applicability of the scheme is ranked, as per Table 7.

Table 7. Comprehensive applicability evaluation results and rankings.

\begin{tabular}{ccc}
\hline $\begin{array}{c}\text { Retail Electricity Price } \\
\text { Package Scheme }\end{array}$ & $\begin{array}{c}\text { Results of Comprehensive } \\
\text { Evaluation of Applicability }\end{array}$ & Ranking \\
\hline Scheme 1 & {$[98.311,19.735,7.203]$} & 2 \\
Scheme 2 & {$[99.041,18.425,6.973]$} & 1 \\
Scheme 3 & {$[96.325,20.591,5.264]$} & 4 \\
Scheme 4 & {$[97.371,19.037,7.405]$} & 3 \\
\hline
\end{tabular}

Table 7 shows the comprehensive evaluation results of the applicability of retail electricity price packages. The expected values of schemes 1, 2, 3 and 4 are 98.311,99.041,96.325 and 97.371 respectively. The expected value of option 2 is the highest, that is, the comprehensive applicability of option 2 is the best, followed by schemes 1,4 and 3 .

The results show that Scheme 2 of retail electricity price package can balance the market demand and supply relationship and adapt to electricity price trend, and has the ability to cope with the uncertainty of consumer electricity consumption and market revenue changes in the electricity market. The electricity selling company has the price advantage in the electricity selling market, which can better adapt to the market competition environment and promote the construction of a complete competitive electricity selling market. Through fair competition, we can optimize the allocation of power resources by market means, so as to improve the efficiency of the whole power industry and reduce the price of electricity.

Comparing the data in Tables 5 and 7 the results are different between the evaluation of the quantitative and comprehensive indexes. For example, the retail electricity price package scheme 1 is ranked first in Table 5, but second in Table 7 . This indicates that qualitative indicators can also affect the applicability of the retail electricity price packages. The comparison results of Scheme 1 are shown in Figure 4, where (2) shows that, after adding the qualitative index, the expectation decreases, the entropy and super entropy increase, and the cloud droplets are more dispersed. Therefore, combining the quantitative indicators with the qualitative ones provides a more accurate scientific evaluation of the applicability of the retail electricity price package.
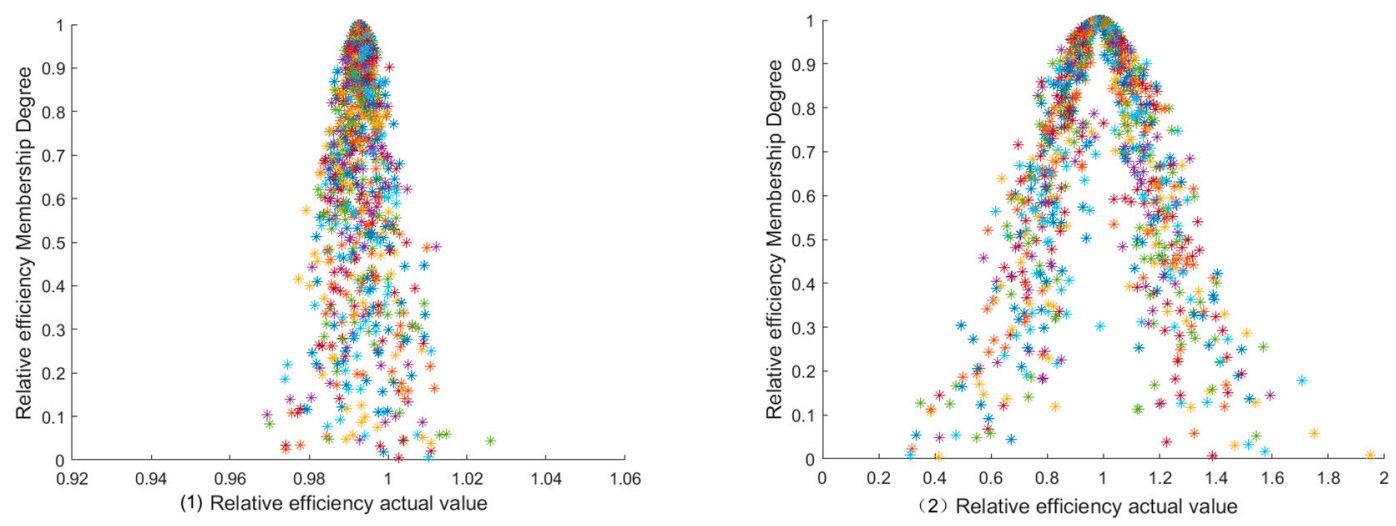

Figure 4. Results comparison of the retail electricity price package Scheme 1. 


\subsection{Robustness Analysis Test}

In order to verify the rationality of the applicability evaluation model of this paper, we further compared four retail electricity price package schemes. By changing the weight calculation method, that is, using the efficiency coefficient entropy method [44] to analyze the sample data, the adaptability evaluation results of each retail electricity price package are calculated; this is consistent with the empirical analysis results of the model constructed in this paper. At the same time, considering the for-profit electricity retail companies, the customer lifetime value of the retail electricity price package is selected to simulate the economic level of the four schemes in one year. The results are shown in Figure 5.

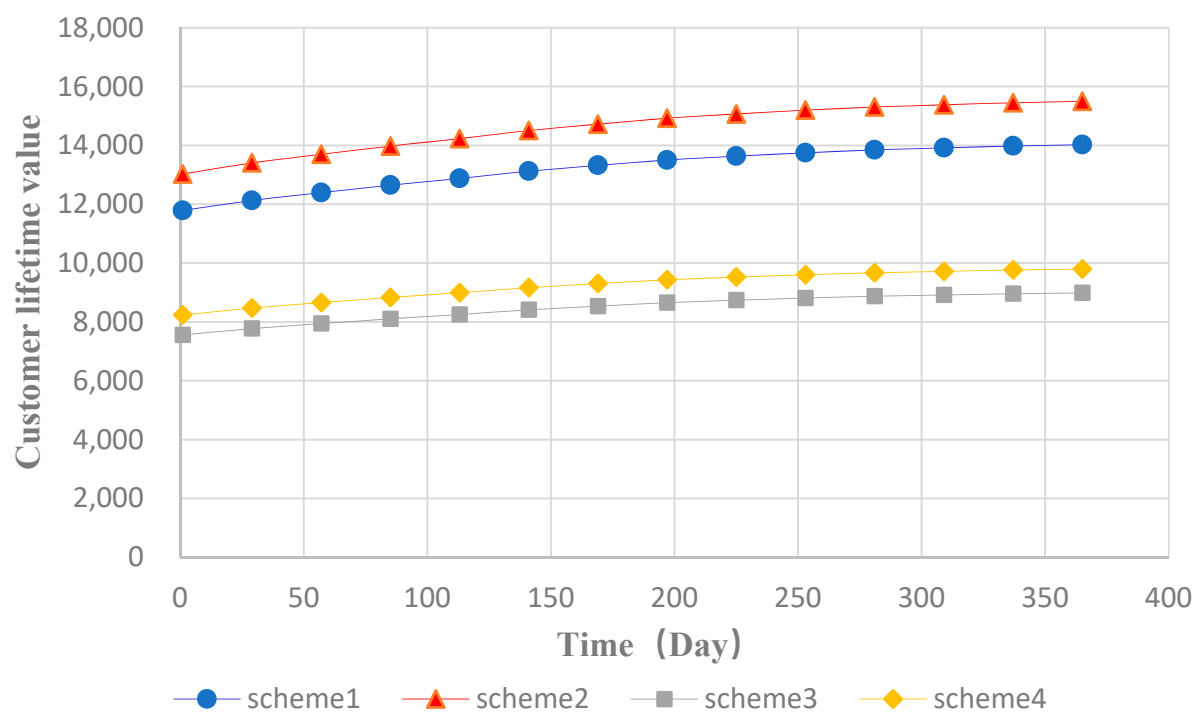

Figure 5. The customer lifetime value of the retail electricity price package.

Figure 5 determines that the economic benefits of the retail electricity price packages are increasing. The customer lifetime value of scheme 2 has always been the largest, followed by Scheme 1, Scheme 4 and Scheme 3, which was consistent with the results of the comprehensive applicability evaluation. This indicates that the comprehensive applicability evaluation model is reasonable.

\section{Conclusions}

We systematically considered the background of the retail electricity market, analyzed the applicable indexes of the retail electricity price package and, finally, proposed a comprehensive evaluation model for the applicability of retail electricity price packages for the retail electricity market. Our conclusions are as follows:

(1) The classic DEA quantitative evaluation method and cloud model qualitative evaluation method were used to construct a comprehensive evaluation model to assess the applicability of the retail electricity price packages. Whilst DEA analyses the quantitative index, the cloud model analyses the qualitative index. The two methods have complementary advantages, making the comprehensive evaluation results better than considering either the quantitative or qualitative indexes alone. Applying the customer lifetime value to verify the rationality of the model ensures the scientific nature of the evaluation results.

(2) DAE was used to analyze the quantitative index of the price package from four seasonal dimensions. The relative evaluation result $\theta$ reflects the applicability of the retail electricity price package, a larger $\theta$ indicates that the retail electricity price package is more applicable, and a smaller $\theta$ indicates that the design of the retail electricity price package has certain problems. Case analysis $\theta$ is relatively small in the summer and winter, which may be affected by temperature, 
and user load transfer is difficult. It is possible to adjust the package to increase the distributed power application and improve the applicability of the retail electricity price package.

(3) The applicability evaluation of the retail electricity price package combines quantitative and qualitative indicators. The case study proves that the introduction of qualitative indicators has a certain impact on the evaluation of electricity price packages. The prices of electricity enterprises are insufficient to adapt to the market price mechanism or to prevent corporate income risks. The overall adaptability of retail electricity price packages can be enhanced by improving the electricity price structure, thus promoting the development of the electricity sales market.

(4) This paper considers the characteristics of China's electricity sales market reform under different stages, the long-term economic benefits of electricity sale companies and the differentiated demand for different electricity consumers. Furthermore, it considers the seasonal fluctuation of user loads and the seasonal differences in electricity price levels across the four periods: spring, summer, autumn and winter. From the three dimensions of the electricity sales market, electricity sales company and users, we analyzed the adaptability level of the retail electricity price package, and give some suggestions to aid their improvement.

Author Contributions: All authors contributed equally to this work. Y.H. proposed the original idea. M.W. completed this paper. F.G. modified and refined the manuscript. All authors have read and agreed to the published version of the manuscript.

Acknowledgments: This study was supported by the Science Technology Project Fund of the State Grid Corporation of China "Research and application of retail price policy under the mode of power sale side liberalization" (SGTYHT/17-JS-199), Fundamental Research Funds for the Central Universities (2019 QN078).

Conflicts of Interest: The authors declare that they have no conflicts of interest.

\section{References}

1. The State Council of the People's Republic of China. Relative Policies on Deepening the Reform of Power Industry. Available online: httlp://www.gov.cn/zhengce/xxgkzl.html (accessed on 1 May 2019).

2. Zeng, M.; Yang, Y.; Wang, L.; Sun, J. The power industry reform in China 2015: Policies, evaluations and solutions. Renew. Sustain. Energy Rev. 2016, 57, 94-110. [CrossRef]

3. Ding, Y.; Hui, H.; Lin, Z.; Zheng, M.; Qu, X.; Cui, W. Design of business model and market framework oriented to active demand response of power demand side. Autom. Electr. Power Syst. 2017, 41, 2-9. (In Chinese)

4. Yang, M.; Bai, H. Understanding household switching behavior in the retail electricity market. Energy Policy 2014, 29, 406-414. [CrossRef]

5. Cavanagh, R.; Levin, A. Rehabilitating Retail Electricity Markets: Pitfalls and Opportunities. In Future of Utilities Utilities of the Future; Elsevier: London, UK, 2016; Chapter 9; pp. 175-192.

6. Bae, M.; Kim, H.; Kim, E.; Chung, A.Y.; Kim, H.; Roh, J.H. Toward electricity retail competition: Survey and case study on technical infrastructure for advanced electricity market system. Appl. Energy 2014, 133, 252-273. [CrossRef]

7. Zhang, S.; Lin, B. Impact of tiered pricing system on China's urban residential electricity consumption: Survey evidences from 14 cities in Guangxi Province. J. Clean. Prod. 2018, 170, 1404-1412. [CrossRef]

8. Loi Tian, S.; Allan, J.G. Electricity market deregulation in Singapore-Initial assessment of wholesale prices. Energy Policy 2019, 127, 1-10.

9. $\mathrm{Wu}, \mathrm{Y}$; Z Zhang, L. Evaluation of energy saving effects of tiered electricity pricing and investigation of the energy saving willingness of residents. Energy Policy 2017, 109, 208-217. [CrossRef]

10. Chen, W.-M. The US electricity market twenty years after restructuring: A review experience in the state of Delaware. Util. Policy 2019, 57, 24-32. [CrossRef]

11. Szoke, T.; Hortay, O.; Balogh, E. Asymmetric price transmission in the Hungarian retail electricity market. Energy Policy 2019, 133, 1-11. [CrossRef]

12. Ahmed, T.; Bhatti, A.A. Do power sector reforms affect electricity prices in selected Asian countries? Energy Policy 2019, 129, 1253-1260. [CrossRef] 
13. Brown, D.P.; Eckert, A. The effect of default rates on retail competition and pricing decisions of competitive retailers: The case of Alberta. Energy Policy 2018, 118, 298-311. [CrossRef]

14. Wang, J.; Dong, J.; Liu, H.; Wang, Y. Green Time-sharing Electricity Price Mechanism and Optimization Based on Demand Response. In Proceedings of the 2018 2nd IEEE Conference on Energy Internet and Energy System Integration, (EI2), Beijing, China, 20-22 October 2018; pp. 210-214.

15. Houman, J.M.; Ahmad, G.; Ahybrid, L. Price-based demand response program for the residential micro-grid. Energy 2019, 185, 274-285.

16. Soares, I.; Alves, M.J.; Antunes, C.H. A population-based approach to the bi-level multifollower problem: An application to the electricity retail market. Int. Trans. Oper. Res. 2019, 35, 90-105. [CrossRef]

17. Li, L.; Yao, Y.; Yang, R.; Zhou, K. Is it more effective to bring time-of-use pricing into increasing block tariffs? Evidence from evaluation of residential electricity price policy in Anhui province. J. Clean. Prod. 2018, 181, 703-716. [CrossRef]

18. Hu, Y.; Li, Y.; Chen, L. Multi-Objective Optimization of Time-of-Use Price for Tertiary Industry Based on Generalized Seasonal Multi-Model Structure. Inst Electr. Electron. Eng. Inc 2019, 7, 89234-89244. [CrossRef]

19. Golmohamad, H.; Keypour, R.; Bak-Jensen, B. Optimization of household energy consumption towards day-ahead retail electricity price in home energy management systems. Sustain. Cities Soc. 2019, 47, 102-119. [CrossRef]

20. Golmohamadi, H.; Keypour, R. Retail Energy Management in Electricity Markets: Structure, Challenges and Economic Aspects-A Review. Technol. Econ. Smart Grids Sustain. Energy 2017, 2, 20. [CrossRef]

21. Athukorala, W.; Wilson, C.; Managi, S.; Karunarathnaa, M. Household demand for electricity: The role of market distortions and prices in competition policy. Energy Policy 2019, 134, 1-10. [CrossRef]

22. Shu, J.; Guan, R.; Wu, L. A Bi-Level Approach for Determining Optimal Dynamic Retail Electricity Pricing of Large Industrial Customers. IEEE Trans. Smart Grid 2019, 10, 2267-2277. [CrossRef]

23. Monfared, H.J.; Ghasemi, A. Retail electricity pricing based on the value of electricity for consumers. Sustain. Energy Grids Netw. 2019, 18, 100205. [CrossRef]

24. Zhu, J.; Vaghefi, S.A.; Jafari, M.A. Managing demand uncertainty with cost-for-deviation retail pricing. Energy Build. 2016, 118, 46-56. [CrossRef]

25. Khojasteh, M.; Jadid, S. Reliability-constraint energy acquisition strategy for electricity retailers. Energy Syst. 2018, 101, 223-233. [CrossRef]

26. Hartley, P.; Medlock, K.; Jankovska, O. Electricity reform and retail pricing in Texas. Energy Econ. 2019, 80, 1-11. [CrossRef]

27. Bai, Z.; Huang, M.; Wu, B. A data envelopment analysis model for evaluating the performance of taxi operators: A case study in Harbin, China. Transp. Plan. Technol. 2019, 42, 662-678.

28. Matthias, E.; Allen, H.; Omid, N. Uncertain Data Envelopment Analysis. Eur. J. Oper. Res. 2018, 268, $231-242$.

29. Shu, T.; Zhong, X.; Zhang, S. TFP Electricity Consumption Efficiency and Influencing Factor Analysis Based on DEA Method. Energy Procedia 2011, 12, 91-97. [CrossRef]

30. Patricia, Z.-C.; Carlos, P.; Josep, M.M.-S. Electricity mix assessment of the EU member countries using DEA and EffMixF. Comput. Aided Chem. Eng. 2018, 43, 445-450.

31. Charles, V.; Aparicio, J.; Zhu, J. The curse of dimensionality of decision-making units: A simple approach to increase the discriminatory power of data envelopment analysis. Eur. J. Oper. Res. 2019, 279, 929-940. [CrossRef]

32. Tao, M.; Qu, R.; Ke, Z. The Cloud Model Theory of Intelligent Control Method for Non-Minimum-Phase and Non-Self-Balancing System in Nuclear Power. In Proceedings of the 26th International Conference on Nuclear Engineering, London, UK, 22-26 July 2018; pp. 1-13.

33. Wang, G.; Xu, C.; Li, D. Generic normal cloud model. Inf. Sci. 2014, 280, 1-15. [CrossRef]

34. Cui, C.-Q.; Wang, B. China's regional sustainability assessment on mineral resources: Results from an improved analytic hierarchy process-based normal cloud model. J. Clean. Prod. 2019, 210, 105-120. [CrossRef]

35. Song, W.; Zhu, J. A multistage risk decision making method for normal cloud model considering behavior characteristics. Appl. Soft Comput. 2019, 78, 393-406. [CrossRef]

36. Dawei, S.; Meng, Y.; Hongkun, B. A Comprehensive Evaluation Model of Power Market Operation Efficiency Based on Extension Cloud Theory. Energy Procedia 2019, 156, 302-309. [CrossRef]

37. Haghighi, A.T.; Ashraf, F.B.; Riml, J.; Koskelac, J.; Kløvea, B.; Marttilaa, H. A power market-based operation support model for sub-daily hydropower regulation practices. Applied Energy 2019, 255, 1-12. 
38. Liu, D.; Liu, R.; Luo, C. Path Optimization Method of Electricity Market Efficiency Based on Structural Equa tion. Autom. Electr. Power Syst. 2016, 40, 479-488.

39. Ren, Y.; Zhou, M.; Li, G. Bi-level Model of Electricity Procurement and Sale Strategies for Electricity Retailers Considering Users' Demand Response. Autom. Electr. Power Syst. 2017, 41, 30-36.

40. Ji, S.; Li, D. Research on Intelligent Electricity EnergyScheduling Method Based on User's Satisfaction. J. Electr. Eng. 2017, 41, 30-36.

41. Ou, Y.; Hu, R.; Sun, T. Research on Customer Selection Probability of Electricity Retailers Based on Market Dynamics and Multi-Agent Technologies. Electr. Power Inf. Commun. Technol. 2018, 7, 8-15.

42. Huang, P.; Li, J.; Li, Y. Research on post-transformation evaluation of scientific and technological achievements of state grid corporation of China based on DEA. Manag. Res. Sci. Technol. Achiev. 2016, 1, 21-24.

43. Wu, D.; Ling, W.; Wang, J. Enterprise production safety evaluation based on cloud model. Inf. Technol. Informatiz. 2016, 193, 76-79.

44. Zhu, X.; Wei, G. Discussion on the Standard of Non-dimensional Method in Entropy Method. Stat. Decis. 2015, 28, 12-15.

(C) 2019 by the authors. Licensee MDPI, Basel, Switzerland. This article is an open access article distributed under the terms and conditions of the Creative Commons Attribution (CC BY) license (http://creativecommons.org/licenses/by/4.0/). 